\title{
ASPECTES JURÍDICS DE LES TELEVISIONS AUTONÒMIQUES EN EL PANORAMA TELEVISIU ESPANYOL
}

\author{
MANUEL ALCARAZ RAMOS \\ Profesor Escuela Universitaria
}

\begin{abstract}
PONENCIA PRESENTADA EN: «I CONGRÉS DE MITJANS DE COMUNICACIÓ».
\end{abstract} (XXI PREMIS OCTUBRE. VALÈNCIA, 1992).

\section{Peculiaritat nacional i peculiaritat televisiva en la transició democràtica}

La transició democràtica espanyola s'enfrontà, entre d'altres, amb un problema essencial: la configuració d'un Estat en el que el reconeixement de les peculiaritats nacionals - $\mathrm{i}$ fins $\mathrm{i}$ tot regionals - fora suficient per evitar majors demandes populars $i$, alhora, fora suficientment restringit com per evitar mejors alarmes en el que s'anomenaren els poders fàctics. Aquest fet és sobradament conegut i si bé és indispensable recordar-lo també és innecesari insisitir ara en la qüestió i en la seua posterior evolució que, en qualsevol cas, donà com a resultat la construcció d'un «Estat autonòmic» amb autonomies de divers grau, varietats que es manifestaven en el desenvolupament competencial i, en definitiva, amb els diferents nivells d'autogovern.

Però la transició també hagué d'enforntar-se amb altres problemes menors els quals, atesa la situació, adquirien un relleu insospitat. Un d'ells era el del fufur de la televisió. Ara bé, és evident que havien quedat enrera els temps en què el ministre responsable de la televisió deia que cada nit jeia tranquil perquè TVE contribuïa a la salvació de les ànimes dels espanyols... Però el model heretat era fill directe d'eixa màquina de salvació per a la que fou creada la televisió a Espanya.

I, lògicament, era un model insostenible. Un aparell car, pesat i corrupte, estretament lligat a la pretesa perpetuïtat ideològica del franquisme $i$, particularment, directament destinat a la promoció de l'homogeneïtat nacional espanyola. Aquest panorama era criticat per les forces polítiques amb presència, però amb el model reformista i no rupturista que se seguia era difícil propiciar els canvis necessaris en la televisió.

Efectivament, la mateixa força que posaven els partits de l'oposició per a criticar la televisió realment existent era un argument fàctic perquè certs sectors d'UCD - 
i fins i tot del franquisme sociològic i ideològic - persistiren en la necessitat de controlar un instrument de poder bàsic. Evidentment, parlar de televisions regionals, autonòmiques, etc., no era més que un projecte esbossat en els caps d'alguns nacionalistes.

En qualsevol cas la suma del problema nacional-autonòmic i de la crisi permanent de TVE amb la primera transició es troba en el propi origen del model que finalment se seguiria. Solament si s'entén aquest fet s'arriba a entendre per què les peculiaritats del model autonòmic televisiu en l'estat espanyol.

\section{El plantejament constitucional i el desenvolupament estatutari}

Es convenient fer constar que els problemes als quals hem fet al.lusió troben el seu reflexe adequat en la Constitució espanyola del 1978, malgrat que això no signifiqués, en molts casos, la inmediata aplicació pràctica dels preceptes constitucionals. A pesar d'això s'estableixen unes bases de desenvolupament posterior inneludibles i malgrat les crítiques fonamentades que se'n puguen fer, és indubtable que després dels pronunciaments de la Carta Magna l'apropament polític a les qüestions nacionals hauria de ser-ne un de ben diferent del que fins aleshores s'havia practicat.

Una cosa semblant va passar amb el panorama audiovisual espanyol: pel que fa a aquesta qüestió podem recordar sobretor l'importantíssim article 20 de la Constitució espányola que desenvolupava de forma extensa el dret a la llibertat d'expressió en llurs múltiples variants, i hi incloïael següent apartat... «LaLleiregularà l'organització i el control parlamentari dels mitjans de comunicació social depenents de l'estat... qualsevol ens público i garantirà l'accés a aquest mitjans dels grups socials i polítics significatius, tot respectant el pluralisme de la societat i de les diverses llengües d'Espanya».

D'altra banda l'article 149.27 va atribuir com a competència exclusiva a l'Estat les «normes bàsiques de règim de premsa, ràdio i televisió i, en general, de tots els mitjans de comunicació social, sota perjudici de les facultats que en el seu desenvolupament i execució pertoquen a les Comunitats Autònomes».

Aquesta al.lusió a les competències televisives tingué consegüentment un reflex en els Estatuts d'Autonomia aprovats, ja que tots ells —amb la relativa excepció del d'Extremadura - inclouen alguna referència ala qüestió. Per no estendre'ns en la descripció dels textos estatutaris indicarem només que els Estatuts de les següents Comunitats Autònomes ja advertien sobre la possibilitat de crear i regular el funcionament d'una televisió pròpia: País Basc, Catalunya, Galícia, Andalusia, Comunitat Vaelnciana, Canàries, Navarra, Baleares. D'altra banda, altres Estatuts eren més ambigus en limitar-se a esperar la concessió d'un tercer canal, com ara els casos, entre d'altres, de Madrid, Aragó o Castella-Lleó1.

\footnotetext{
${ }^{1}$ Per als textos legals: «Legislación sobre la radio y la televisión», Dirección Gral. de Medios de Comunicación Social y B.O.E. Madrid, 1990.
} 


\section{La reforma en el panorama audiovisual i la televisió autonòmica: Estatut de la Ràdio i la Televisió, Lley de tercers canals i Lley de les televisions privades ${ }^{2}$.}

L'inici de la transició radiotelevisiva es verificà amb l'aprovació de l'Estatut de la ràdio i la televisió (Llei 4/1980, de 10 de gener) que de manera no sempre feliç regulava tant el funcionament de RTVE com, genèricament, el de la ràdio i televisió a l'Estat espanyol -és a dir, les ràdios que existien o pogueren existir, TVE i les televisions que pogueren existir en el futur.

Aquest Estatut recollia algunes al.lusions a la nova realitat autonòmica de l'Estat; aixi:

-El Preàmbul atribuia a la radiodifusió i la televisió, enteses com a servei públic, la funció de difondre «la cultura espanyola i les seues nacionalitats i regions».

-El mateix preàmbul advertia, un poc confusament, sobre «la possibilitat d'establir un canal de televisió de titularitat estatal per a l'àmbit territorial de cada Comunitat Autònoma i sota la seva gestió, que es complementa amb un significatiu grau de participació en els òrgans territorials de RTVE».

-Aquest mandat començava a desenvolupar-se en l'article 2n, 2: «El Govern podrà concedir a la Comunitat Autònoma, prèvia autorització per Llei de les Corts Generals, la gestió directa d'un canal de televisió de titularitat estatal que es cree específicament per a l'àmbit territorial de cada Comunitat Autònoma». Els paràgraf següents del mateix article es referien als criteris de funcionament dels tercers canals i atribuïa es exclussiva al Govern de l'Estat l'aplicació d'Acords i Convenis Internacionals en allò que quests pogueren afectar els canals autonòmics.

—D'altra banda, els articles 13, 14 i 15 —Secció 6a, del Capítol II- feien referència a l'organització territorial de RTVE centrada en:

- programació específica per a les Comunitats Autònomes;

-Delegat Territorial de RTVE;

- Consell Assessor territorial nomenat per «l'òrgan de govern de la Comunitat Autònoma».

La següent norma fonamental en la matèria fou la Llei reguladora del Tercer Canal de Televisió (Llei 46/1983, del 26 de desembre) que era el resultat del que preveu l'article 2n. de l'Estatut de Ràdio y Televisió. En la pràctica el seu article 1r.

\footnotetext{
${ }^{2}$ Per raons d'espai no abordarem algunes disposicions de caràcter tàcnic que en general reforcen els òrgans centrals front els autonòmics amb la Llei Orgànica de Telecomunicacions o el Real Decret d'aprovació de l'estatut de «Retevisión». Igualment, ens centraren exclusivament en la televisió, tot deixant de banda els comentaris sobre les emissions de ràdio que ens obligarien a remetre'ns a una legislació diferent en alguns casos i a un panorama també diferent.
} 
autoritzava el Govern a prendre les mesures oportunes per al funcionament d'un tercer canal de televisió de titularitat estatal i atorgar-lo «en règim de concessió» en l'àmbit de cada «comunitat Autònoma» a petició dels òrgans de govern d'aquestes, segons la legalitat vigent.

El problema principal se'n deriva de la interpretació que caldria fer sobre l'obligatorietat per al Govern d'atorgar la concessió una vegada acomplerts els requisits o si haurien de primar criteris d'oportunitat política per modular les concessions - com finalmente s'actuà- la qual cosa, tanmateix, recordava simbòlicament la primacia del poder central davant els poders autonòmics que no tenien capacitat legal si no era «derivada» per comptar amb els seus propis medis televisius.

A més a més, altres trests d'aquesta Llei serien:

-L'Estat proporcionaria la xarxa d'emissores, enllaços i reemissors i cada Comunitat Atònoma abonaria un cànon anual.

- L'activitat dels Tercers Canals s'adequaria a principis democràtics i constitucionals emblans als fixats per a RTVE. Això mateix es pot dir dels mecanismes de gestió.

-Es permetia als Tercers Canals l'establiment de convenis.

—Les societats concessionàires no podrien «adquirir en exclusiva programes que impedesquen la seua projecció en un àmbit territorial diferent al de la seua pròpia comunitat...»

- Cas d'existir concurrència per a l'adquisició d'un mateix programa entre una societat concessionària d'un tercer canal d'una Comunitat Autònoma amb llengua pròpia i l'Ens Públic de TRVE, aquella podrà en qualsevol cas adquirir el mateix programa per emetre'l en la llengua pròpia de la Comunitat.

-Es reservava a RTVE la prioritat en retransmissions «en directe» d'esdeveniments esportius internacionals, podent però, previ pagament d'un canon, retransmetre'ls els tercers canals en les seues llengües pròpies.

-El finançament dels tercers canals es faria:

- subvencions dels Pressupostos de les Comunitats Autònomes;

— comerciatlizació i venda de productes;

-publicitat.

Finalment, ens correspon fer un sucint comentari a la Llei de la televisió privada (Llei 10/1988 de 3 de maig). Precisament el comentari ha de ser breu perquè en cap dels seus articles es desprén directament l'interés o l'obligació per a aquests canals privats d'emetre atenent a algun criteri mínimament descentralitzat.

Després d'aquesta superficial anàlisi de la lletra de les principals normes sobre la televisió en l'Estat espanyol podem extreure les següents conclusions provisionals sobre el panorama legal: 
1.- La preocupació pel pluralisme nacional, regional i lingüístic és quelcom «reservat» a les televisions públiques i no a les privades.

2.- RTVE, segons la Constitució i el Pràmbul de l'Estatut de la Ràdio i la Televisió, hauria de ser un òrgan que reflectira i difonguera el pluralisme regional i nacional de l'Estat. Tanmateix, en la pràctica, s'ha produït una descentralització funcional variable segons criteris essencialmen econòmics i tècnics i no culturals i/ o polítics. Excepte en el cas català, en quasi cap altre territori els centres territorials de TVE han tingut la independència $i$ les dotacions que permeteren una diversitat en les programacions. D'altra banda, també s'ha renunciat, per exemple, a un model britànic d'especialització dels centres territorials en determinats tipus de productes. Para.lelament a aquestes decisions estratègiques les figures dels Directors Territorials i dels Consells Assessors Territorials han quedat pràcticament inèdites o molt difumninades. En definitiva, podem afirmar que a pesar de desconnexions i d'altres experiències parcials, RTVE no ha estat ni és un model de respecte i promoció de les cultures regionals i nacionals al qual estaria obligat pel seu caràcter públic estatal - d'un Estat plurinacional-i pel seu propi estatut ${ }^{3}$.

3.- Malgrat les limitacions i entrebancs legals els tercers canals autonòmics estaven destinats a convertir-se en els únics capaços de cobrir el buit deixat per la resta de televisions. Com ho han fet serà matèria per a les següents reflexions.

\section{Els canals autonòmics.}

Com ja hem indicat l'inici de les emissions depenia de què el Govern atorgara la pertinent llicència mitjançant un Decret. Malgrat que en el cas català hi hagué emissions ja abans de la llicència, en general podem afirmar que els principals problemes se'n derivaren dels retards, solament comprensibles per raons polítiques, en la concessió de llicències a Comunitats Autònomes sol.licitants i que reunien tots els requisits formals.

Després de la inicial posada en funcionament de les televisions catalana, basca i gallega, Andalusia, Madrid i el País Valencià hagueren d'esperar uns anys —amb les respectives lleis aprovades pels seus parlaments - per obtenir les llicències ${ }^{4}$.

Actualment a més d'aquestes sis entitats cal cridar l'atenció sobre diverses gestions desenvolupades a Aragó, Murcia, Navarra, Canàries i Balears. Per raons

\footnotetext{
${ }^{3}$ Sobre els Centres Territorials de RTVE: VV.AA. Jornadas sobre el papel de la T.V. estatal en las Comunidades Autónomas. Consell Assessor de RTVE. Comunitat Valenciana. Editor: José Reig Cruañes. València, 1991. Dins d'aquesta obra i per el tema, consultar: P. Hernández, Modelos de la TV pública central, p. 21 i ss. J. Montesinos, El futuro de la TV pública central: especialización y territorialización, p. 43 i ss. F. Parrila, Los CC. TT. de TVE y su realización con los canales autonómicos, p. 131. M. Alcaraz Ramos, Florencia o Youville. Sobre cultura, descentralización y modelos televisivos, p. 177 i ss.

${ }^{4}$ C. Chinchilla Martín. La radiotelevisión como servicio público esencial, p. 155 i ss.
} 
pràctiques podem fer un balanç tot centrant-nos en les lleis dels sis ens que emeten en aquest moment i que podem sintetitzar de la següent manera:

1.- Gestió directa del servei públic televisió —a diferència de les televisions provades que segueixen un model de «gestió indirecta» ${ }^{5}$.

2.- Televisions públiques, que, amb independ:encia de les crítiques justificades que se'n puguen fer a les seues programacions, significa:

-control parlamentari directe ${ }^{6}$;

—extracció «política» dels òrgans de direcció;

-finançament, parcial, via pressupostos autonòmics;

—obligacions o «càrregues» específiques $\mathrm{i}$, entre elles, especial atenció a la cultura pròpia i, si s'escau, a les llegües propies;

—previsió — si bé és quasi inèdita— de participació en l'assessorament i en la programació d'organismes socials, culturals, religiosos, sindicals, etc. ${ }^{7}$.

3.- Model mixt de direcció amb un Consell d'Administració designat pels parlaments Autonòmics i un Director General.

4.- Trets de funcionament formals semblants als que estableix l'Estatut per a RTVE amb especial atenció al respecte a valors democràtics i constitucionals.

5.- Sistema de gestió —amb societats mercantils— semblant al de RTVE.

Amb aquestes dades podem afirmar que:

1.- Les lleis autonòmiques seguiren puntualment i sense problemes la llei del Tercer Canal i l'Estatut de la Ràdio i la Televisió.

2.- En allò en què el marge de discrecionalitat era més gran la imaginació fou reduïda, i es copià potser massa el model de RTVE, la qual cosa donà lloc de vegades a necessàries modificacions o condemnà òrgans a la ineficàcia —per exemple: les Presidències rotatives del Consell d'Administració.

3.- Una part de l'articulat de les Lleis de Creació autonòmica no s'han desenvolupat per manca de voluntat política $\mathrm{i} / \mathrm{o}$ perquè s'entenien com a qüestions disfuncionals des d'una lògica de rendabilitat mercantil: així, per exemple:

- previsions sobre la participació d'entitats o grups socials significatius;

-Consells Assessors amb representació dels treballadors dels mitjans;

-instituts destinats a la formació professional;

—en el cas valencià: la renúncia a integrar la televisió en un procés global i estratègicament planificat de normalització lingüística.

${ }^{5}$ Idem. P. 61 i ss.

${ }^{6}$ J. L. Pérez Francesch. El control parlamentario de los medios de comunicación públicos. A: «Libertad de expresión»; V. A. B. Anuario 1990, p. 131 i ss.

${ }^{7}$ E. Alonso i A. Montoro. Radio televisión regional y participación social. A: E. Linde i altres. Las rediotelevisiones en el espacio europeo. RTVV, València, 1990. P. 295 i ss. 
Malgrat aquestes deficiències el model espanyol de canals autonòmics és única a Europa perquè representen televisions públiques depenents directament d'òrgans polítics diferents dels de l'Estat central i que no emeten en cadena, és a dir, que gaudeixen d'elevada autonomia respecte d'un centre polític però també entre elles.

Aquest fet ens permet una valoració global positiva de l'existència de les televisions autonòmiques, al menys per aquestes raons:

1) Han reforçat considerablement la consciència regional i nacional en les diverses comunitats, tot permetent als ciutadans una autoidentificació simbòlica de gran relleu.

2) Generalment, han estat un poderòs mitjà per a la recuperació i normalització lingüística i per a la dinamització sociocultural.

3) Malgrat les crítiques que se'ls puguen fer han contribuït a definir un espai públic televisiu en un camp i en un temps en els quals aquest espai no podia ser representat per RTVE. Això ha fet que les televisions autonòmiques hagen trobat un clar buit en les audiències de les seues comunitats i que, fins a cert punt, eviten el desolador panorama promés - $\mathrm{i}$ acomplert dia a dia - per les televisions privades.

Per finalitzar, voldria oferir unes notes sobre el futur, la qual cosa, d'alguna manera, és una espècie d'oferiment de conclusions.

En primer lloc, s'escau de preguntar-se per la «quantitat» de televisions autonòmiques. La resposta és incerta perquè, com he advertit, diverses Comunitats han aprovat lleis de creació i fins i tot han constituit Consells d'Administració o han posat en funcionament emissores radiofòniques. Tanmateix, no crec que en un termini raonable apareguen, a molt estirar, una o dues televisions autonòmiques noves i això, al menys, per tres raons:

- la crisi econòmica obliga a retallar els pressupostos i fa impossibles les inversions en infraestructura;

-l'existencia de televisions privades fa molt difícil que les inversions publicitàries ja «captives» en un mercat saturat puguen desviar-se suficientment cap a noves televisions;

- hi ha una campanya contra la televisió pública de la dreta que fa molt difícils les iniciatives consensuades en projectes com aquest.

Per tant el panorama sembla restringir-se a l'evolució dels sis ens — vuit canals-existents. Sense entrar en anàlisis detallades d'evolució econòmica sembla certa que el seu futur pot dependre d'una paradoxa, de la negació del que fins ara era la seua principal característica: la seau independència absoluta. Efectivament: les tres raons que fan difícil posar en marxa noves televisions afavoreixen objetivament el desenvolupament de la FORTA —Federació d'Organitzacions de Ràdio i Televisió Autonòmiques—, de manera que puguera passar-se dels «Tercers Canals» a un atèntic «Tercer Canal», encara que la seua cobertura no abastara el conjunt del territori de l'Estat. 
En qualsevol cas aquesta hipòtesi, crec, mai no arribarà a ser una realitat absoluta. Raons legals i, sobretot, polítiques, s'hi oposen. La cessió de «sobirania» que hauria de fer cada televisió segurament limitarà les possibilitats d'avançar amb més decisió. Tanmateix, ni que siga com a tendència, cal entendre que aquesta no solament és possible sinó que, des de certs punts de vista tècnics és necessària, inquiestionable. Dit això, però, cal advertir també dels perills i el primer és que la primacia de la tècnica desplace altres apreciacions intrínseques a una televisió pública. El millor exemple: una evolució simplement tècnica de laFORTA significaria una absència de control públic de les emissions per la qual cosa sembla necessari agilitzar la constitució d'òrgans estables de representants dels Consells d'Administració de les entitats que integren la federació.

No s'acaba ací la qüestió: aconseguir les audiències - $\mathrm{i}$ els consegüents ingressos publicitaris-que fan viable el manteniment de les televisions autonòmiques exigeix, en primer lloc, que la seua pròpia existència com a televisions públiques, regionals o nacionals, es revalide dia a dia, la qual cosa significa reafirmar allò peculiar, polititzar el que podria quedar en pur intercanvi de folclorismes: en definitiva, es tracta de fer unes televisions que no pertanyen a països abstractes sinó d'homes i dones amb llengües, cultures i històries que en fer-se concretes els pertanyen, els identifiquen $i$ els facen reals $i$ que han d'expressar-se lliurement $i$ participar lliurement en les seues televisions i no ser només telespectadors passius de programes enllaunats a Tòquio i a Los Àngeles. 